\title{
Front Matter: Volume 7654
}

, "Front Matter: Volume 7654," Proc. SPIE 7654, 5th International Symposium on Advanced Optical Manufacturing and Testing Technologies: Large Mirrors and Telescopes, 765401 (20 October 2010); doi: 10.1117/12.877493

SDE Event: 5th International Symposium on Advanced Optical Manufacturing and Testing Technologies, 2010, Dalian, China 


\title{
PROCEEDINGS OF SPIE
}

\section{5th International Symposium on Advanced Optical Manufacturing and Testing Technologies \\ Large Mirrors and Telescopes}

\author{
Wenhan Jiang \\ Myung K. Cho \\ Fan Wu \\ Editors
}

\section{6-29 April 2010 \\ Dalian, China}

Sponsored by

COS-The Chinese Optical Society (China) • IOE-The Institute of Optics and Electronics, CAS (China)

\section{Cosponsor}

SPIE

Supporting Organizations

Ministry of Science and Technology of China (China) • Chinese Academy of Sciences (China)

National Natural Science Foundation of China (China)

Cooperating Organizations

Fraunhofer Institute for Applied Optics and Precision Engineering (Germany) • Singapore Institute of Optics and

Photonics (Singapore) • Optical Society of Sichuan Province (China) • State Key Laboratory of Microfabrication

(China) - Dalian Institute of Chemical Physics, CAS (China) - Dalian University of Technology (China) • Changchun

Institute of Optics, Fine Mechanics and Physics, CAS (China) • Changchun University of Technology (China) - National

University of Defense Technology (China) • University of Electronic Science and Technology of China (China) • Harbin

Institute of Technology (China) • Beijing Institute of Technology (China) • Crystechcoating Inc. (China)

Published by

SPIE

Volume 7654 
The papers included in this volume were part of the technical conference cited on the cover and title page. Papers were selected and subject to review by the editors and conference program committee. Some conference presentations may not be available for publication. The papers published in these proceedings reflect the work and thoughts of the authors and are published herein as submitted. The publisher is not responsible for the validity of the information or for any outcomes resulting from reliance thereon.

Please use the following format to cite material from this book:

Author(s), "Title of Paper," in 5th International Symposium on Advanced Optical Manufacturing and Testing Technologies: Large Mirrors and Telescopes, edited by Wenhan Jiang, Myung K. Cho, Fan Wu, Proceedings of SPIE Vol. 7654 (SPIE, Bellingham, WA, 2010) Article CID Number.

ISSN 0277-786X

ISBN 9780819480842

Published by

SPIE

P.O. Box 10, Bellingham, Washington $98227-0010$ USA

Telephone +1 3606763290 (Pacific Time) · Fax +1 3606471445

SPIE.org

Copyright (C) 2010, Society of Photo-Optical Instrumentation Engineers

Copying of material in this book for internal or personal use, or for the internal or personal use of specific clients, beyond the fair use provisions granted by the U.S. Copyright Law is authorized by SPIE subject to payment of copying fees. The Transactional Reporting Service base fee for this volume is $\$ 18.00$ per article (or portion thereof), which should be paid directly to the Copyright Clearance Center (CCC), 222 Rosewood Drive, Danvers, MA 01923. Payment may also be made electronically through CCC Online at copyright.com. Other copying for republication, resale, advertising or promotion, or any form of systematic or multiple reproduction of any material in this book is prohibited except with permission in writing from the publisher. The CCC fee code is 0277-786X/10/\$18.00.

Printed in the United States of America.

Publication of record for individual papers is online in the SPIE Digital Library.

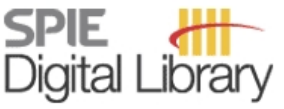

SPIEDigitalLibrary.org

Paper Numbering: Proceedings of SPIE follow an e-First publication model, with papers published first online and then in print and on CD-ROM. Papers are published as they are submitted and meet publication criteria. A unique, consistent, permanent citation identifier (CID) number is assigned to each article at the time of the first publication. Utilization of CIDs allows articles to be fully citable as soon they are published online, and connects the same identifier to all online, print, and electronic versions of the publication. SPIE uses a six-digit CID article numbering system in which:

- The first four digits correspond to the SPIE volume number.

- The last two digits indicate publication order within the volume using a Base 36 numbering system employing both numerals and letters. These two-number sets start with 00, 01, 02, 03, 04 , 05, 06, 07, 08, 09, OA, OB ... 0Z, followed by 10-1Z, 20-2Z, etc.

The CID number appears on each page of the manuscript. The complete citation is used on the first page, and an abbreviated version on subsequent pages. Numbers in the index correspond to the last two digits of the six-digit CID number. 


\title{
Contents
}

\author{
ix Symposium Committee \\ xi Conference Committee \\ xiii Introduction
}

\section{SESSION 1-1}

765402 Research on technique of wavefront retrieval based on Foucault test [7654-31]

L. Yuan, Nanjing Institute of Astronomical Optics \& Technology (China); Z. Wu, Nanjing Institute of Astronomical Optics \& Technology (China) and Graduate Univ. of Chinese Academy of Sciences (China)

765404 Research of active supporting technology based on 400mm thin mirror [7654-16] H. Li, X. Liu, J. Wang, Changchun Institute of Optics, Fine Mechanics and Physics (China)

765405 Study on computer-aided alignment method of Cassegrain system [7654-100] W. Bin, J. S. Lei, Q. Tian, Institute of Optics and Electronics (China)

765406 Blind deconvolution in phased telescope array [7654-11]

Z. Zhou, D. Wang, Y. Wang, Y. Wan, Beijing Univ. of Technology (China)

765407 The accuracy problem of FEA in the deformation of larger-aperture optical components [7654-23]

S. Li, R. Zhang, Sichuan Univ. (China)

765408 Fabrication of large off-axis asymmetry aspherics using stressed lap with orbital tool motion [7654-36]

X. Luo, L. Zheng, X. Zhang, Changchun Institute of Optics, Fine Mechanics and Physics

(China) and Graduate Univ. of Chinese Academy of Science (China)

SESSION 1-2

765409 Grinding and Grinding and polishing technology by computer controlled active lap for \$1250mmF/1.5 aspheric mirror [7654-500]

B. Fan, Z. Zeng, X. Li, Q. Chen, P. Gao, J. Zhou, Y. Wan, Institute of Optics and Electronics (China)

7654 OA Nonlinear analysis method for predicting optical surface deformations resulted from assembly process [7654-38]

W. Dong, Y. Yong, J. Guang, Changchun Institute of Optics, Fine Mechanics and Physics (China)

7654 OB Development plan of Korea for the GMT [7654-24]

Y.-S. Kim, Korea Astronomy and Space Science Institute (Korea, Republic of) 
7654 OC Dynamic auto-collimation method for performance inspection of optical tracking devices with gimbaled mirrors [7654-30]

M. Gao, Z. Bian, Z. Dong, Q. Ye, R. Qu, Shanghai Institute of Optics and Fine Mechanics (China)

7654 OD Research on a diamond turning method for large aspherical mirrors [7654-47]

C.-S. Han, L.-J. Zhang, Y. Ren, T. Sun, Harbin Institute of Technology (China)

$7654 \mathrm{OE}$ The application of wavefront coding technology to a large segmented synthetic aperture telescope [7654-53]

L. Feng, J. Meng, X. Dun, Y. Tao, L. Zhu, X. Wu, Z. Zhang, C. Zhang, X. Chen, L. Lei, K. Zhao, Tianjin Jinhang Institute of Technical Physics (China)

7654 OF Studying on working tolerance of off-axis three-mirror anastigmatic telescope [7654-32] Q. Yu, F. Chen, Shanghai Institute of Technical Physics (China); Y. Xu, Taiyuan Satellite Launch Ctr. (China)

\section{POSTER SESSION}

7654 OG Athermalization of coaxial reflective space telescope [7654-37]

Z. Lei, J. Guang, Changchun Institute of Optics, Fine Mechanics and Physics (China)

7654 OH Design control system of telescope force actuators based on WLAN [7654-04]

X. Shuai, Chizhou College (China); Z. Zhang, Nanjing Institute of Astronomical Optics \& Technology (China)

7654 Ol Research on primary mirror lateral support structure of large-aperture telescope [7654-83] Y. Wang, Jilin Agricultural Univ. (China)

7654 0J Research on axial support technology of large aperture primary mirror [7654-54] H. Yao, Changchun UP Optotech Co., Ltd. (China)

7654 OK Design and control of the precise tracking bed based on complex electromechanical design theory [7654-66]

C. Ren, Z. Liu, L. Wu, K. Chen, Tsinghua Univ. (China)

$7654 \mathrm{OL}$ The simulation of the Antarctic Robotic Telescope model based on VC [7654-52]

W. Zhou, Nanjing Institute of Astronomical Optics \& Technology (China) and Graduate Univ. of Chinese Academy of Sciences (China); H. Wang, Nanjing Institute of Astronomical Optics \& Technology (China)

7654 OM Application of research for metal primary mirror of large-aperture infrared solar telescope [7654-35]

X. Meng, Nanjing Institute of Astronomical Optics \& Technology (China) and Graduate Univ. of Chinese Academy of Sciences (China); H. Zhang, X. Li, Nanjing Institute of Astronomical Optics \& Technology (China) 
$7654 \mathrm{ON}$ Research on edge control in the process of polishing using ultra precise bonnet on optical elements [7654-41]

W. Wang, Shanghai Modern Advanced Ultra Precision Manufacturing Ctr. (China); M. Xu, Fudan Univ. (China); G. Yu, D. D. Walker, Technium OpTIC (United Kingdom); H. Zhu, Shanghai Modern Advanced Ultra Precision Manufacturing Ctr. (China)

765400 Improved uniformity of target irradiation by combining an Orthogonal Cylindrical Lens Array and the polarization control [7654-40]

J. Zheng, Dalian Univ. of Technology (China) and Dalian Nationalities Univ. (China);

W. Zheng, Beijing Univ. of Cemecal Technology (China); Q. Yu, Dalian Univ. of Technology

(China); B. Dong, Dalian Nationalities Univ. (China); S. Guan, Y. Wu, Dalian Univ. of

Technology (China) and Dalian Nationalities Univ. (China)

7654 OP Wavefront alignment research of segmented mirror Synthetic Aperture Optical (SAO) system [7654-60]

J. Deng, X. An, SouthernWest Institute of Technical Physics (China); H. Tian, Harbin Institute of Technology (China)

$76540 Q \quad$ Study on the azimuth bearing scheme of a large Alt-azimuth telescope [7654-43] H. Wang, J. Zhang, S. Dai, Changchun Institute of Optics, Fine Mechanics and Physics (China)

$7654 \mathrm{OR}$ Study on response function of the ultra thin circular mirror with very large aperture [7654-19] Y. Feng, R. Zhang, Sichuan Univ. (China)

7654 OS Wavefront control for complicated pupil space telescopes [7654-06] Q. Wu, Suzhou Univ. of Science and Technology (China); F. Wu, Changzhou Institute of Technology (China) and Soochow Univ. (China); L. Qian, Soochow Univ. (China)

7654 OT The influence of contaminated mirror on the flux distributions of stray radiation of infrared telescope systems [7654-84]

P. He, J. Xiao, B. Zhang, X. Yao, Sichuan Univ. (China)

7654 OU Path analysis and suppression of self-generated thermal emission in infrared optical systems [7654-67]

X. Yao, J. Xiao, B. Zhang, S. Zeng, P. He, Sichuan Univ. (China)

$7654 \mathrm{OV}$ The influence of the thermal environment on the stray light performances of infrared telescope systems [7654-48]

J. Xiao, X. Yao, B. Zhang, S. Zeng, P. He, Sichuan Univ. (China)

7654 OW Ground-based measurement of the space object temperature [7654-21]

G. Wang, Y. Wu, J. Wang, J. Zhao, Changchun Institute of Optics, Fine Mechanics and Physics (China)

7654 0X Co-phasing of segmented mirrors using Dispersed Rayleigh Interferometry in the presence of background star [7654-58]

S. Wang, Q. Zhu, T. Huang, Beijing Insititute of Technology (China)

7654 OY Sub-aperture stitching with scanning pentaprism testing optical wave-front [7654-57]

L. Wang, W. Yang, L. Li, S. WU, Z. Lin, Institute of Optics and Electronics (China) 
$7654 \mathrm{OZ}$ Study on remote sensing imaging system based on phase diversity [7654-64]

F. Li, Institute of Optics and Electronics (China) and Key Lab. on Adaptive Optics (China) and National Univ. of Defense Technology (China); C. Rao, W. Jiang, Institute of Optics and Electronics (China) and Key Lab. on Adaptive Optics (China)

765410 Joining of silicon carbide ceramic for optical application by reaction bonded technology [7654-13]

A. Zhang, Y. Chen, Z. Chen, H. Liu, J. Fang, Institute of Optics and Electronics (China)

765411 The optical and electrochemical properties of electrochromic films: $\mathrm{WO}_{3}+\mathrm{xV}_{2} \mathrm{O}_{5}$ [7654-59] Z. Li, H. Liu, Y. Liu, S. Yang, Y. Liu, C. Wang, Naval Univ. of Engineering (China)

765412 Analysis of requirements of actuator performance for $1.2 \mathrm{~m}$ active primary mirror under gravity load [7654-44]

J. Zhang, P. Yao, Institute of Optics and Electronics (China) and The Key Lab. on Adaptive Optics (China) and Graduate School of Chinese Academy of Sciences (China); X. Zhang, Y. Zhang, Institute of Optics and Electronics (China) and The Key Lab. On Adaptive Optics (China)

765413 Closed-loop experiment of two deformable mirrors adaptive optics system compensating for amplitude and phase fluctuations [7654-63]

H. Yu, Institute of Optics and Electronics (China) and Key Lab. on Adaptive Optics (China) and National Univ. of Defense Technology (China); L. Huang, Institute of Optics and Electronics (China) and Key Lab. on Adaptive Optics (China); L. Huang, Institute of Optics and Electronics (China) and Sichuan Univ. (China); D. Cai, Institute of Optics and Electronics (China) and Taiyuan Univ. of Technology (China); C. Rao, W. Jiang, Institute of Optics and Electronics (China) and Key Lab. on Adaptive Optics (China)

765414 Time-delay analysis for dynamic surveying of the laser total station measurement system for FAST [7654-97]

X. Zhai, L. Zhu, National Astronomical Observatories (China)

765415 Imaging characteristics of an optical butting camera [7654-10]

H. Lei, Z. Xu, H. Feng, Q. Li, Zhejiang Univ. (China)

765416 Research of active panel technology for large aperture millimeter-wave/sub-millimeter-wave telescope [7654-92]

X. Wu, Nanjing Institute of Astronomical Optics \& Technology (China) and Graduate Univ. of Chinese Academy of Sciences (China); X. Cui, Nanjing Institute of Astronomical Optics \& Technology (China)

765417 Performance study of a $\mathbf{1 . 2}$ m active mirror [7654-50]

P. Yao, Institute of Optics and Electronics (China) and The Key Lab. on Adaptive Optics (China) and Graduate School of the Chinese Academy of Sciences (China); X. Zhang, Institute of Optics and Electronics (China) and The Key Lab. on Adaptive Optics (China); J. Zhang, Institute of Optics and Electronics (China) and The Key Lab. on Adaptive Optics (China) and Graduate School of the Chinese Academy of Sciences (China); Y. Zhang, Institute of Optics and Electronics (China) and The Key Lab. on Adaptive Optics (China)

765418 Study of the shock wave effects to the laser transmission at the supersonic speed [7654-26] X. Zhang, N. Shen, H. Zhang, X. Wang, Nanjing Univ. of Science \& Technology (China) 
765419 Misalignment wavefront detection of large segmented aperture optical system on-orbit [7654-12]

L. Lu, W. Zhang, Harbin Institute of Technology (China)

7654 1A Analysis and simulation of the surface shape of membrane mirror applied by non-uniform load [7654-20]

G. Zhang, Jiangsu Key Lab. of Modern Optical Technology (China) and Institute of Information Optics Engineering (China); M. Tang, Jiangsu Key Lab. of Modern Optical Technology (China) and Institute of Information Optics Engineering (China) and Soochow Univ. (China); J. Yu, W. Shen, Jiangsu Key Lab. of Modern Optical Technology (China) and Soochow Univ. (China)

7654 1B Manufacture of $\mathbf{\$ 1 . 2 m}$ reaction bonded silicon carbide mirror blank [7654-42] G. Zhang, R. Zhao, W. Zhao, J. Bao, Changchun Institute of Optics, Fine Mechanics and Physics (China)

7654 1C Fabrication of composite structures based on microwrinkles [7654-96]

X. Zhao, Harbin Institute of Technology (China); W. An, Northeast Forestry Univ. (China); H. Yu, China Electronics Technology Group Corp. (China); L. Wang, Harbin Institute of Technology (China)

7654 1D Application for vibration monitoring of aspheric surface machining based on wireless sensor networks [7654-15]

C. G. Han, Xiamen Univ. (China) and Ningbo Dahongying Univ. (China); Y. B. Guo, C. Jiang, Xiamen Univ. (China)

7654 1E Research on high precision membrane mirror forming method [7654-45]

C. Liu, Changchun Institute of Optics (China) and Graduate School of Chinese Academy of Sciences (China); J. Jia, G. Jin, Changchun Institute of Optics (China); X. Zhong, Changchun Institute of Optics (China) and Graduate School of Chinese Academy of Sciences (China); S. Gu, Changchun Institute of Optics (China)

$7654 \mathrm{IF} \quad$ Analysis of bonding stress with high strength adhesive between the reflector and the mounts in space camera [7654-93]

Y. Li, Y. Hu, Y. Li, Y. Qu, J. Ding, Xi'an Institute of Optics and Precision Mechanics (China)

$76541 \mathrm{G}$ Wavefront error budget and optical manufacturing tolerance analysis for $1.8 \mathrm{~m}$ telescope system [7654-51]

K. Wei, Institute of Optics and Electronics (China) and The Key Lab. on Adaptive Optics (China) and Graduate School of Chinese Academy of Sciences (China); X. Zhang, H. Xian, C. Rao, Y. Zhang, Institute of Optics and Electronics (China) and The Key Lab. on Adaptive Optics (China)

$76541 \mathrm{H} \quad$ First observations on the 127-element adaptive optical system for 1.8m telescope [7654-28] C. Rao, Institute of Optics and Electronics (China) and The Key Lab. on Adaptive Optics (China); K. Wei, X. Zhang, Institute of Optics and Electronics (China) and The Key Lab. on Adaptive Optics (China) and Graduate School of Chinese Academy of Sciences (China); A. Zhang, Y. Zhang, H. Xian, L. Zhou, C. Guan, M. Li, D. Chen, S. Chen, Y. Tian, Z. Liao, Institute of Optics and Electronics (China) and The Key Lab. on Adaptive Optics (China) 
$765411 \quad$ Exposure of space camera prediction with radiative transfer software PcModWin [7654-90] D. Xie, Z. Xu, H. Feng, Zhejiang Univ. (China)

$76541 \mathrm{~J} \quad$ Large mirror lightweight method based on temperature control strategy [7654-98] F. Tan, F. Long, Harbin Institute of Technology (China)

$76541 \mathrm{~K}$ Design and precision performance research of exact constraint support structure [7654-61] X. Chen, W. Wu, X. Fu, Y. Xu, China Academy of Engineering Physics (China)

$76541 \mathrm{~L} \quad$ Compositing Images for an optical butting camera [7654-09] Z. Xu, H. Lei, H. Feng, Q. Li, C. Dai, Zhejiang Univ. (China)

$76541 \mathrm{M} \quad$ A support method of large aperture light weighted primary mirror manufacturing and testing [7654-22]

Y. Zhao, Y. Zhou, C. Li, Beijing Institute of Space Mechanics \& Electricity (China)

$76541 \mathrm{~N}$ Design of compensating and testing system of primary mirror with a 500mm diameter [7654-101]

L. Fu, G. Zhou, T. Li, Shanghai Astronautic Institute of Control and Technology (China)

765410 Some methods for the fabrication of large diameter off-axis paraboloids [7654-88]

D. Li, Nanjing Institute of Astronomical Optics \& Technology (China); X. Chen, Nanjing Astronomical Instrument Co. Ltd. (China)

7654 1P The compensation tests of ellipsoidal mirror with a scale of $1 \mathrm{~m}$ and super large relative aperture [7654-85]

J. Pan, Nanjing Astronomical Instrument Research Ctr. (China) and Graduate School of Chinese Academy of Sciences (China); M. Hu, Nanjing Astronomical Instrument Co. Ltd. (China); S. Shen, Nanjing Astronomical Instrument Research Ctr. (China) and Graduate School of Chinese Academy of Sciences (China); X.-C. Liu, Nanjing Astronomical Instrument Co. Ltd. (China)

Author Index 


\title{
Symposium Committees
}

\author{
Honorary Chair
}

Daheng Wang, Chinese Academy of Sciences (China) and Chinese Academy of Engineering (China)

Symposium General Chair

Bingkun Zhou, Chinese Optical Society (China) and Chinese Academy of Sciences (China)

Symposium General Cochairs

Jianlin Cao, Ministry of Science and Technology of China (China)

James C. Wyant, College of Optical Sciences, The University of Arizona (United States)

Yudong Zhang, Institute of Optics and Electronics, CAS (China)

Michael Pfeffer, German Institute of Applied Optics (Germany)

Peigeng Li, Huazhong University of Science \& Technology (China) and Chinese Academy of Engineering (China)

Guofan Jing, Tsinghua University (China) and Chinese Academy of Engineering (China)

Chunhao Zhang, China Association for Science (China), Chinese Academy of Sciences (China), and Dalian Institute of Chemical Physics (China)

International Academic Committee

Wenhan Jiang, Chair, Chinese Academy of Engineering (China) and Institute of Optics and Electronics, CAS (China)

Fengting Sang, Chinese Academy of Engineering (China) and Dalian Institute of Chemical Physics, CAS (China)

Lishi Wen, Chinese Academy of Engineering (China) and Dalian University of Technology (China)

Guoguang Mu, Chinese Academy of Sciences (China) and Nankai University (China)

Yijun Zhao, Chinese Academy of Engineering (China) and National University of Defense Technology (China)

Xingdan Chen, Chinese Academy of Engineering (China) and Changchun Institute of Optics, Fine Mechanics and Physics, CAS (China)

Dianyuan Fan, Chinese Academy of Engineering (China) and Shanghai Institute of Optics and Fine Mechanics, CAS (China)

Liding Wang, Chinese Academy of Sciences (China) and Dalian University of Technology (China) 
Junhua Pan, Chinese Academy of Engineering (China) and Soochow University (China)

Junhao Chu, Chinese Academy of Sciences (China) and Shanghai Institute of Technical Physics, CAS (China)

Liwei,Zhou Chinese Academy of Engineering (China) and Beijing Institute of Technology (China)

Roland Geyl, Sagem SA (France)

Jose M. Sasian, College of Optical Sciences, The UniversityofArizona (United States)

Fritz Klocke, Fraunhofer Institute for Production Technology IPT (Germany)

James R. Torley, University of Colorado at Colorado Springs (United States)

Yoshiharu Namba, Chubu University (Japan)

James H. Burge, College of Optical Sciences, The University of Arizona (United States)

David D. Walker, University College London (United Kingdom)

\section{Organizing Committee}

Yudong Zhang, Chair, Institute of Optics and Electronics, CAS (China)

Jinghua Cao, Cochair, Chinese Academy of Sciences (China)

Libin Xiang, Cochair, Academy of Optoelectronics, CAS (China)

Anand Asundi, Cochair, Nanyang Technological University (Singapore)

Guoqiang Ni, Cochair, Chinese Optical Society (China)

Program Committee

Xiangdi Lin, Chair, Chinese Academy of Engineering (China)

Hu Yang, Cochair, Institute of Optics and Electronics, CAS (China)

Yuwen Qing, Cochair, Natural Science Foundation of China (China)

Haodong Yu, Cochair, Changchun University of Science and Technology (China)

Sen Han, Cochair, Veeco Instruments Inc. (United States)

Myung K. Cho, Cochair, National Optical Astronomy Observatory (United States)

Secretary General of the Symposium

Li Yang, Committee of Optical Manufacturing Technology, COS (China) Jinxue Wang, SPIE 


\title{
Conference Committee
}

\author{
Conference Chairs \\ Wenhan Jiang, Institute of Optics and Electronics, CAS (China) \\ Myung K. Cho, National Optical Astronomy Observatory \\ (United States) \\ Fan Wu, Institute of Optics and Electronics, CAS (China) \\ Session Chairs \\ Session 1-1 \\ Fan Wu, Institute of Optics and Electronics, CAS (China)
}

Session 1-2

Bin Fan, Institute of Optics and Electronics, CAS (China) 
Downloaded From: https://www.spiedigitallibrary.org/conference-proceedings-of-spie on 26 Apr 2023

Terms of Use: https://www.spiedigitallibrary.org/terms-of-use 


\section{Introduction}

The 5th International Symposium on Advanced Optical Manufacturing and Testing technologies (AOMATT) was held 26-29 April 2010 at Dalian World Expo Center in the beautiful city of Dalian, China. This is the same venue where the 2007 World Economy Forum of DAVOS was held. AOMATT was initiated in 2000 to provide a forum for international researchers, designers, managers, and manufacturers to discuss related technologies in this area. The first meeting, AOMATT 2000, was held in Chengdu, China. Since then, AOMATT has increasingly become a must-attend conference for the international optical design, manufacturing, and testing communities. AOMATT has developed a reputation for excellent plenary sessions, quality oral and poster papers, and fun social events.

AOMATT 2010 was opened with a grand opening ceremony and outstanding plenary sessions. About 1,000 delegates attended the opening ceremony and plenary sessions in the multi-functional hall of the Dalian World Expo Center. Honored guests and sponsoring and cooperating organization representatives, including Professor Qing Yu Weng representing the National Science Foundation of China (NSFC), Dr. Jinxue Wang representing SPIE, technical cosponsor of AOMATT, and Dr. James C. Wyant, Dean of Optical Sciences at the University of Arizona and 2010 president of OSA, gave welcome and congratulation speeches at the opening ceremony. Professor Guofan Jin, an academician of the Chinese Academy of Engineering and cochair of the symposium, gave an opening speech in written form on behalf of the Chinese Optical Society (COS). Plenary speakers included Dr. Roland Geyl from REOSC of France, Dr. Hong Minghui from the National University of Singapore, Dr. Yoshiharu Namba from Chubu University of Japan, Dr. James Wyant from the University of Arizona in the USA, Dr. Thomas Franz from the NTG Company in Germany, Professor Fengting Sang, an academician from the Dalian Institute of Chemical Physics, Chinese Academy of Sciences (CAS), and Professor Xiangqun Cui, an academician from the Nanjing Institute of Astronomical Optics and Technology, National Astronomical Observatory, CAS. Other academicians attending AOMATT 2010 included: Wenhan Jiang from IOE of CAS, Can Li from DICP of CAS, Junhua Pan from Suzhou University, Liwei Zhou from Beijing Institute of Technology, and Yijun Zhao from the National University of Defense Technology.

AOMATT 2010 received more than 1,300 abstracts. After careful reviews by the conference chairs and committee members and an invited reviewer, more than 700 papers were accepted for presentation at the conference and publication in the Proceedings of SPIE. The AOMATT 2010 proceedings are divided into six volumes - 7654-7659 - and correspond to the six conferences of the symposium, namely, Large Mirrors and Telescopes; Advanced Optical Manufacturing Technologies; Optical Test and Measurement Technology and Equipment; 
Design, Manufacturing, and Testing of Micro- and Nano-Optical Devices and Systems; Optical Materials, Detectors, Imagers, and Energy Conversion Technology; and Smart Structures and Materials in Manufacturing and Testing.

There is continued improvement in paper quality compared to previous AOMATT symposiums. Many papers report cutting-edge research and development. More authors are from well-known universities, research institutions, and corporations around the world. We believe AOMATT 2010 made another important step in establishing itself as an essential international symposium for the international optical design, manufacturing, and testing communities.

We would like to express our sincere appreciation to COS-The Chinese Optical Society, IOE-Institute of Optics and Electronics, the Chinese Academy of Sciences, and to SPIE for supporting AOMATT. We want to thank all the authors and participants for attending the symposium and sharing their research with colleagues around the world. We especially thank IOE and Dr. Yudong Zhang, President of IOE, for their steadfast support of AOMATT since its inception in 2000.

We look forward to your participation and support of the 6th AOMATT in 2012. Location, time, and the call for papers will be posted on SPIE and IOE websites soon. 